Communications in Physics, Vol. 23, No. 2 (2013), pp. 147-153

\title{
FABRICATION AND MAGNETIC PROPERTIES OF $\mathrm{Nd}_{2} \mathrm{Fe}_{14} \mathrm{~B} / \mathrm{Fe}_{65} \mathrm{Co}_{35}$ HARD MAGNETIC RIBBONS
}

\author{
NGUYEN XUAN TRUONG \\ Institute of Materials Science, \\ Vietnam Academy of Science and Technology, \\ 18 Hoang Quoc Viet, Cau Giay, Hanoi, Vietnam \\ NGUYEN VAN KHANH \\ Hanoi National University of Education \\ 136 Xuan Thuy Street, Cau Giay District, Vietnam \\ Received 01 April 2013; revised manuscript received 27 May 2013 \\ Accepted for publication 21 May 2013
}

\begin{abstract}
Nd}_{2} \mathrm{Fe}_{14} \mathrm{~B} / \mathrm{Fe}_{65} \mathrm{Co}_{35}$ hard magnetic ribbons were fabricated by melt-spinning technique using $\mathrm{Nd}_{16} \mathrm{Fe}_{76} \mathrm{~B}_{8}$ and $\mathrm{Fe}_{65} \mathrm{Co}_{35}$ pre-alloys as starting materials. The results showed that the formation of the interactive hard/soft nanocomposite with the homogeneous distribution of the FeCo phase throughout the $\mathrm{Nd}_{2} \mathrm{Fe}_{14} B$ matrix provided the Curie temperature $\left(T_{c}\right)$ as high as $747 \mathrm{~K}$, the magnetic remanence $\left(B_{r}\right)$ of $8.88 \mathrm{kG}$ and the maximum energy product, $(\mathrm{BH})_{\max }$, of 16.75 $M G$. Oe for the fabricated $\mathrm{Nd}_{2} \mathrm{Fe}_{14} \mathrm{~B} / \mathrm{Fe}_{65} \mathrm{Co}_{35}$ ribbons at the optimal speed of $25 \mathrm{~m} / \mathrm{s}$. In addition, the intrinsic coercivity $\left({ }_{i} H_{c}\right)$ of $9.27 \mathrm{kOe}$ and remanence coercivity $\left.{ }_{b} H_{c}\right)$ of $6.94 \mathrm{kOe}$ were found for these ribbons. The roles of the soft $\mathrm{Fe}_{65} \mathrm{Co}_{35}$ phase in the increasing of $T_{c}, B_{r}$ as well as in the (00l) preferred crystallographic orientation of hard magnetic grains on the free surface side of the fabricated ribbons were also discussed.
\end{abstract}

\section{INTRODUCTION}

Melt-spun $\mathrm{Nd}_{2} \mathrm{Fe}_{14} \mathrm{~B}$-based nanocomposite ribbons have been studied for almost 30 years [1]. The major research on these materials was focused to improve their magnetic properties by controlling the melt-spinning process, changing the ratio of component elements of the original alloy and annealing regime to optimize nanocomposite microstructure. In general, the $(B H)_{\max }$ could get value beyond the threshold of 20 MG.Oe, but mainly the values were given in the range of 12 - 18 MG.Oe [2-12]. As reported the $(B H)_{\text {max }}$ threshold values were achieved by using complex technologies $[13,14]$. For example, the value of 20.3 MG.Oe was achieved in [13] by using a diversity of original alloy ( $\mathrm{Pr}$, $\mathrm{Tb})_{2}(\mathrm{Fe}, \mathrm{Nb}, \mathrm{Zr})_{14} \mathrm{~B} / \alpha$-Fe and with a strict control of microstructure to get an uniform distribution of $\alpha$-Fe, but the repetition of this technology faces many difficulties.

The value of 22 MG.Oe given for a sample with single-phase microstructure and nanocrystalline exchange interaction was reported in the work [15]. The $(B H)_{\max }$ of about 20-22.5 MG.Oe for rapid quenched ribbons was also reported in [16]. However, to achieve these values, a combination of Pr, Dy, and Co elements have been used by many 
authors. These elements increase the freedom degree and thus reduces the stability of the technology processing. Anyway, an important finding by the authors in ref. 16 is that a uniform microstructure of particles in size of $20-35 \mathrm{~nm}$ would significantly improve the quality of the rapid quenched ribbons. Especially, the maximum energy product of 26.2 MG.Oe at room temperature was found for the as-spun $\operatorname{Pr}_{8} \mathrm{Fe}_{75} \mathrm{Co}_{10} \mathrm{NbB}_{5} \mathrm{C}$. It was assumed to be originated from contibutions of the doping of $\mathrm{Pr}, \mathrm{Co}, \mathrm{Nb}$ and $\mathrm{C}$ elements and the homogeneous distribution of NbC phase at grain boundaries of the hard magnetic grains [17]. These above-mentioned preparative techniques that provide such large $(B H)_{\max }$ value, however, it is difficult to be applied.

In this paper, we present the new results in preparation of the melt-spun $\mathrm{Nd}_{16} \mathrm{Fe}_{76} \mathrm{~B}_{8} /$ $30 \%$ wt. $\mathrm{Fe}_{65} \mathrm{Co}_{35}$ ribbons at optimal speed of $25 \mathrm{~m} / \mathrm{s}$. The addition of $\mathrm{Fe}_{65} \mathrm{Co}_{35}$ alloy with high saturation magnetic $\left(240 \mathrm{emu} / \mathrm{g}\right.$ ) has improved the remanence of $\mathrm{Nd}_{2} \mathrm{Fe}_{14} \mathrm{~B} / \mathrm{Fe}_{65} \mathrm{Co}_{35}$ ribbons. Besides the role of $\mathrm{Fe}_{65} \mathrm{Co}_{35}$ in the increasing of $T_{c}$ and magnetic properties of $\mathrm{Nd}_{2} \mathrm{Fe}_{14} \mathrm{~B} / \mathrm{Fe}_{65} \mathrm{Co}_{35}$ ribbons also were observed and discussed in details.

\section{EXPERIMENTS}

The pre-alloys with nominal compositions of $\mathrm{Fe}_{65} \mathrm{Co}_{35}$ and $\mathrm{Nd}_{16} \mathrm{Fe}_{76} \mathrm{~B}_{8}$ were prepared by an arc-melting method from Nd, Fe, Co powders and a FeB alloy under $\mathrm{Ar}$ atmosphere. The ingots were melted three times to obtain a high homogeneity. In a typical procedure, 20-22g pre-alloy mixture with $\mathrm{Fe}_{65} \mathrm{Co}_{35}$ amount of $30 \%$ in weight of $\mathrm{Nd}_{16} \mathrm{Fe}_{76} \mathrm{~B}_{8}$ was melted spun onto a cooper wheel under $0.05 \mathrm{MPa}$ Argon atmosphere from a quartz tube. The melt-spinning was operated at the wheel speed ranged from 20 to $30 \mathrm{~m} / \mathrm{s}$ to find an optimal wheel speed. The quartz tube orifice diameter was fixed at $1.0 \mathrm{~mm}$, the distance between the nozzle and the wheel surface was kept constant by $4 \mathrm{~mm}$. Structural and surface morphological studies were carried out using a SIEMENS D5000 $\mathrm{X}$-ray diffractometer $(\mathrm{XRD})$ with $\mathrm{Cu}-\mathrm{K} \alpha$ radiation. Phase composition analysis using the JADE software with Rietveld refinement option for the full width half maximum (FWHM) analysis of peaks taken in the $2 \theta$ range from $22^{\circ}$ to $88^{\circ}$. The morphology of ribbon was studied by using Hitachi-S4800 field emission scanning electron microscopy (FESEM). The hysteresis loops of ribbons were measured by the physical property measurement system (PPMS 6000). A vibrating sample magnetometer (VSM) was employed to measure the thermal magnetization curve of ribbons.

\section{RESULTS AND DISCUSSION}

Fig. 1 shows the $\mathrm{XRD}$ pattern of $\mathrm{Nd}_{16} \mathrm{Fe}_{76} \mathrm{~B}_{8}$ alloyed using arc-melting. The diffraction peak at 2-theta angle of $31^{\circ}$ was assigned to elemental $\mathrm{Nd}$ phase, while all other diffraction peaks belong to the $\mathrm{Nd}_{2} \mathrm{Fe}_{14} \mathrm{~B}$ phase. The excess $\mathrm{Nd}$ amount of about $3 \%$ wt. of $\mathrm{Nd}_{16} \mathrm{Fe}_{76} \mathrm{~B}_{8}$ pre-alloy was derived from Rietveld analysis.

From the diffraction diagram of $\mathrm{Fe}_{65} \mathrm{Co}_{35}$ pre-alloy sample showed in Fig. 2, one can realize that all diffraction peaks were assigned to $\mathrm{Fe}_{65} \mathrm{Co}_{35}$ phase and no other impurity phase was detected. Saturation magnetization of this pre-alloy was measured by using PPMS 6000 and $\mathrm{M}_{s}$ value of $240 \mathrm{emu} / \mathrm{g}$ was achieved (Fig. 5a). 


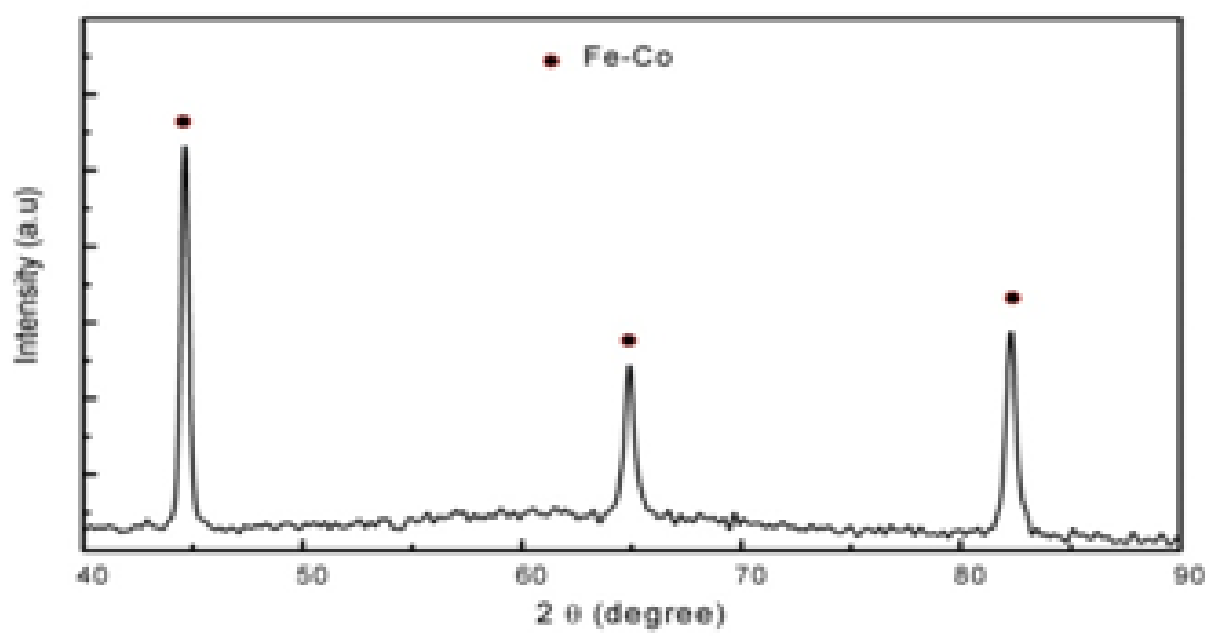

Fig. 1. XRD diagram of $\mathrm{Nd}_{16} \mathrm{Fe}_{76} \mathrm{~B}_{8}$ alloy sample.

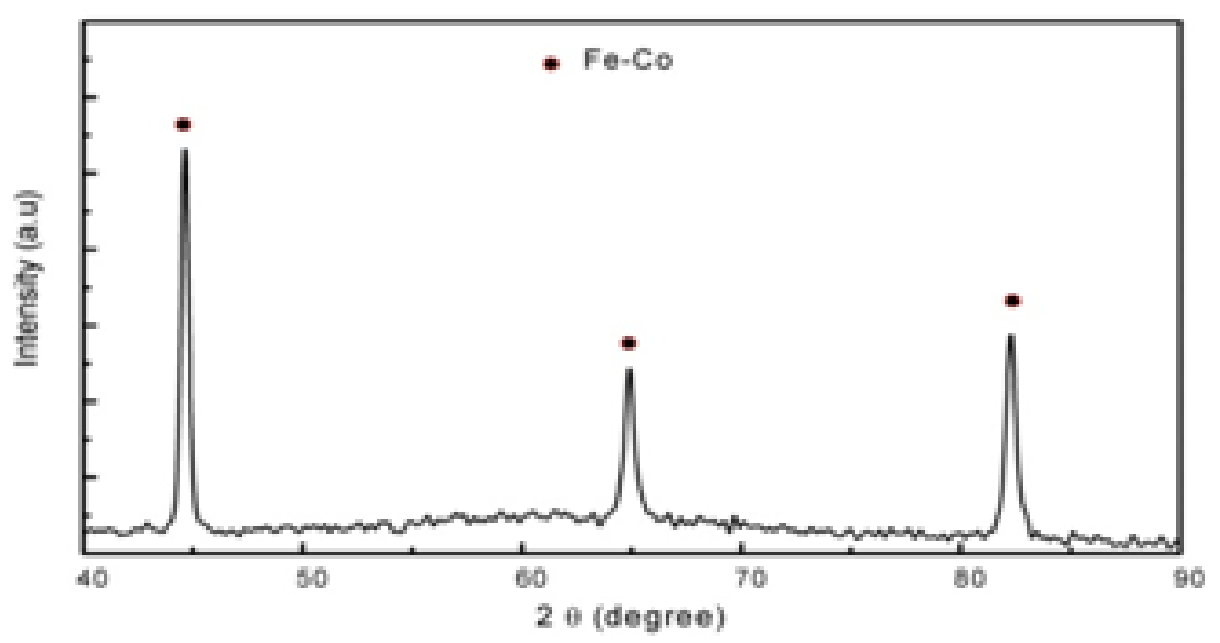

Fig. 2. XRD diagram of the $\mathrm{Fe}_{65} \mathrm{Co}_{35}$ phase.

Fig. 3a and Fig. 3b, present XRD diagrams of the rapid quenched $\mathrm{Nd}_{16} \mathrm{Fe}_{76} \mathrm{~B}_{8} /$ $\mathrm{Fe}_{65} \mathrm{Co}_{35}(30 \% \mathrm{wt})$ measured at the wheel-contacted surface and free surface sides of the ribbon sample. It revealed that the $\mathrm{Nd}_{2} \mathrm{Fe}_{14} \mathrm{~B}$ - based crystalline phase was observed only in the two sides of ribbon, while $\mathrm{Fe}_{65} \mathrm{Co}_{35}$ phase was found only at the free surface side. It is clearly seen that while the random distribution of crystalline grain was found at the contacted surface side of the ribbons (Fig.3a), conversely the (001) preferred orientation growth of crystalline grains at opposite side was clearly observed with a significant increase 


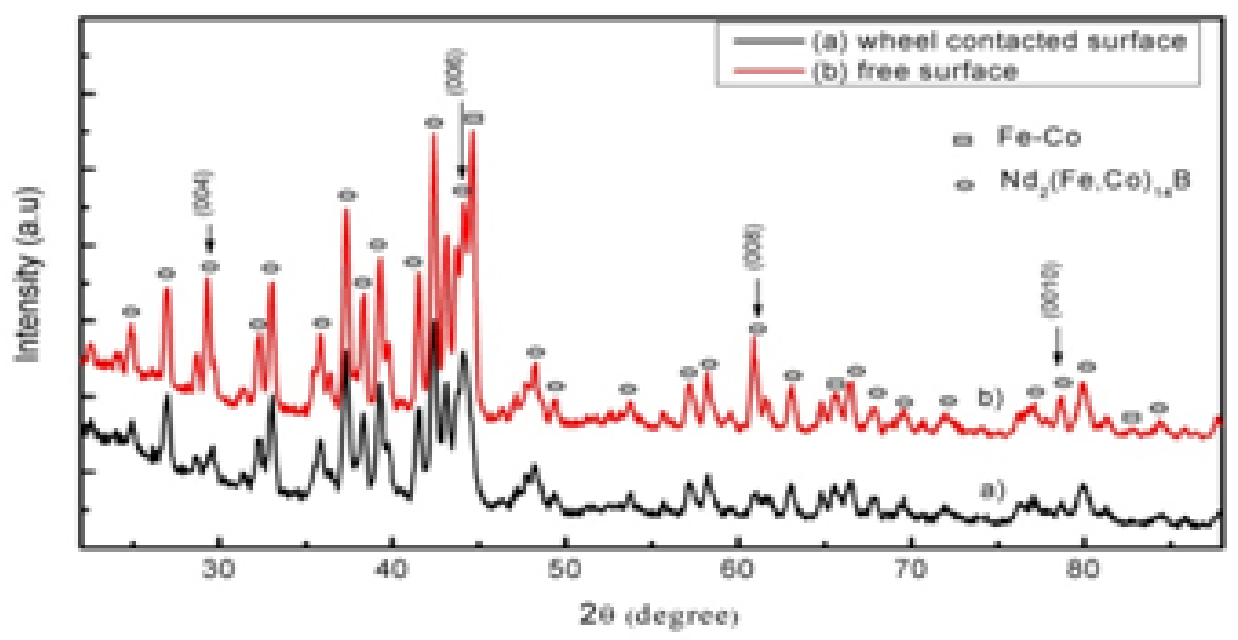

Fig. 3. XDR diagrams of the rapid quenched $\mathrm{Nd}_{16} \mathrm{Fe}_{76} \mathrm{~B}_{8} / 30 \%$ wt. $\mathrm{Fe}_{65} \mathrm{Co}_{35}$ ribbon: a) Wheel contacted surface, b) free suface.

in intensity of (004), (006) and (008) peaks (Fig.3b) [18]. This crystallographic preferred orientation along c-axis perpendicular to the plane of the ribbon can be explained as a result of the presence of $\mathrm{Fe}_{65} \mathrm{Co}_{35}$ in the melt-mixture used with a wheel speed of $25 \mathrm{~m} / \mathrm{s}$ in the spinning technique. With these selected melt-spinning conditions, a suitable thermal gradient rate was achieved and, consequently facilitated the growth processing in the preferred direction. In the case of the thermal gradient rate was not large enough for the grains nucleation a growing the crystalline grains with preferred c-axis orientation were observed also in the wheel-contacted surface side of the ribbons.

To demonstrate the combination of nano-fabrication of ribbons, temperature dependence measurement of magnetization was conducted following a scanning cycle up and down. Representative results of $M(T)$ curve of $\mathrm{Nd}_{16} \mathrm{Fe}_{76} \mathrm{~B}_{8} / 30 \%$ wt. $\mathrm{Fe}_{65} \mathrm{Co}_{35}$ ribbon are shown in Fig. 4. The curve shows clearly a paramagnetic - ferromagnetic phase transition occurred at temperature of $747 \mathrm{~K}$ by substituting $\mathrm{Co}$ for $\mathrm{Fe}$ in the $\mathrm{Nd}_{2} \mathrm{Fe}_{14} \mathrm{~B}$ phase. Beside the curve also shows the existence of the soft magnetic phase $\alpha$-Fe (Fe-Co) with the increase in magnetization at temperature over $T_{c}$ value $(747 \mathrm{~K})$ of the hard magnetic phase.

Fig. 5 displays hysteresis loops measured on $\mathrm{Fe}_{65} \mathrm{Co}_{35}, \mathrm{Nd}_{16} \mathrm{Fe}_{76} \mathrm{~B}_{8}$ and $\mathrm{Nd}_{16} \mathrm{Fe}_{76} \mathrm{~B}_{8} /$ $\mathrm{Fe}_{65} \mathrm{Co}_{35}(30 \% \mathrm{wt})$ samples. The soft magnetic phase $\mathrm{Fe}_{65} \mathrm{Co}_{35}$ has saturation magnetization, $M_{s}$ valued at $240 \mathrm{emu} / \mathrm{g}$ and intrinsic coercivity, ${ }_{i} H_{c}=0$. The magnetic properties of as-spun $\mathrm{Nd}_{16} \mathrm{Fe}_{76} \mathrm{~B}_{8}$ ribbons at optimal speed, $v=18 \mathrm{~m} / \mathrm{s}$, with saturation magnetization $\left(M_{s}\right)$, remanence magnetization $\left(M_{r}\right)$, intrinsic coercivity $\left({ }_{i} H_{c}\right)$ and energy product $(B H)_{\max }$ are $108.4 \mathrm{emu} / \mathrm{g}($ at $H=40 \mathrm{kOe}), 66.8 \mathrm{emu} / \mathrm{g}(6.41 \mathrm{kG}), 14.5 \mathrm{kOe}$ and $8.1 \mathrm{MG} . O e$, respectively. For the fabricated $\mathrm{Nd}_{2} \mathrm{Fe}_{14} \mathrm{~B} / \mathrm{Fe}_{65} \mathrm{Co}_{35}$ ribbons at optimal speed, Curie temperature $\left(T_{c}\right)$, saturation magnetization $\left(M_{s}\right)$, remanence magnetization $\left(M_{r}\right)$, intrinsic coercivity $\left({ }_{i} H_{c}\right)$ and remanence coercivity $\left({ }_{b} H_{c}\right)$ values of $747 \mathrm{~K}, 130,6 \mathrm{emu} / \mathrm{g}$ (at $\mathrm{H}=40$ 


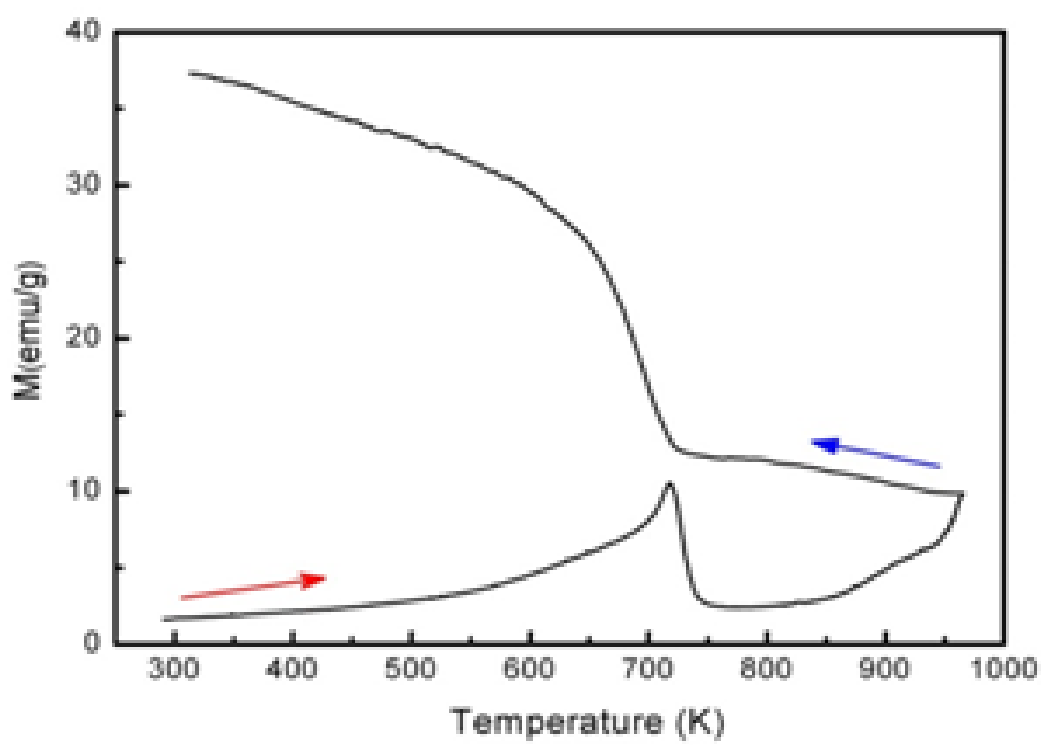

Fig. 4. Thermal magnetic analysis curve of the $\mathrm{Nd}_{16} \mathrm{Fe}_{76} \mathrm{~B}_{8} / 30 \%$ wt. $\mathrm{Fe}_{65} \mathrm{Co}_{35}$ sample.

$\mathrm{kOe}), 89.1 \mathrm{emu} / \mathrm{g}\left(M_{r}=8.88 \mathrm{kG}\right.$ ¿ $M_{s} / 2$ of hard magnetic phase, $\mathrm{Nd}_{2} \mathrm{Fe}_{14} \mathrm{~B}$, with $M_{s}=$ $1.61 \mathrm{kG}), 9.27 \mathrm{kOe}$ and $6.94 \mathrm{kOe}$, respectively, were obtained. Thus, for these nanocomposite ribbons, as significantly improving in the maximum energy product $(B H)_{\max }$ up to 16.75 MGOe was achieved.

Based on the Kneller-Hawig theory [19], it is clear that the quality of nanocomposite magnets depends mainly on the two parameters of the soft magnetic phase: volume fraction and grain size. The volume fraction must be large enough to increase the remanence and the grain sizes must be small enough for strengthening the hardening process. The hysteresis loop of the $\mathrm{Nd}_{16} \mathrm{Fe}_{76} \mathrm{~B}_{8} / \mathrm{Fe}_{65} \mathrm{Co}_{35}(30 \%$ wt) ribbons with high squareness, nonkink and smooth was indicating the coexistence of an exchange coupling between the hard and soft magnetic phases.

From FESEM image of $\mathrm{Nd}_{16} \mathrm{Fe}_{76} \mathrm{~B}_{8} / \mathrm{Fe}_{65} \mathrm{Co}_{35}$ (30\% wt). ribbon showed in Fig. 6, the nano-sized feature of particles was revealed with sizes fell in the range of 50 to 100 $\mathrm{mm}$.

\section{CONCLUSION}

$\mathrm{Nd}_{2} \mathrm{Fe}_{14} \mathrm{~B} / \mathrm{Fe}_{65} \mathrm{Co}_{35}$ ribbons were fabricated by rapid quenching technology with an optimum speed of $25 \mathrm{~m} / \mathrm{s}$. Nanocomposite structure consists of a hard magnetic and a soft magnetic phase which was identified by the XRD, FESEM, $M(H)$ and $M(T)$ measurements. The optimization of technological conditions provided rapid quenched ribbons having a high value magnetic energy of $16.75 \mathrm{MG}$.Oe. Specially, the Curie temperature and the intrinsic coercivity reached $747 \mathrm{~K}$ and $9.27 \mathrm{kOe}$, respectively. This good quality ribbon nanocomposite is promising to produce the bonded magnets for applications. 


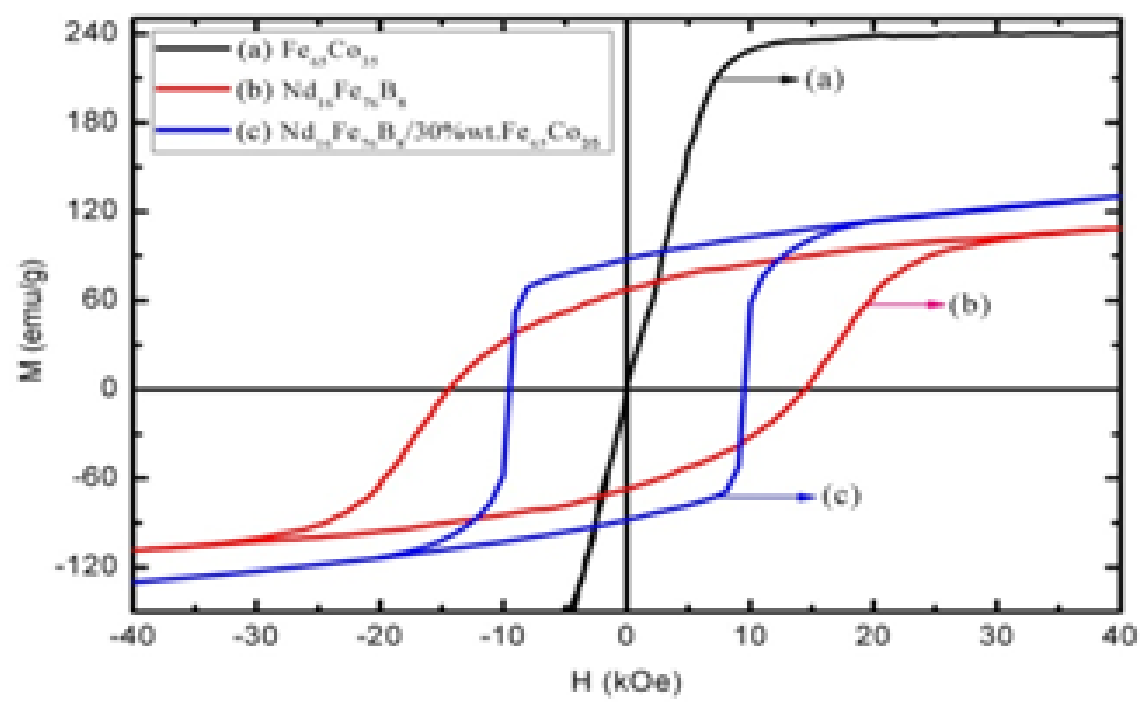

Fig. 5. Hysteresis loops of samples: (a) - $\mathrm{Fe}_{65} \mathrm{Co}_{35}$, (b) $-\mathrm{Nd}_{16} \mathrm{Fe}_{76} \mathrm{~B}_{8}$ and (c) $\mathrm{Nd}_{16} \mathrm{Fe}_{76} \mathrm{~B}_{8} / 30 \%$ wt. $\mathrm{Fe}_{65} \mathrm{Co}_{35}$.

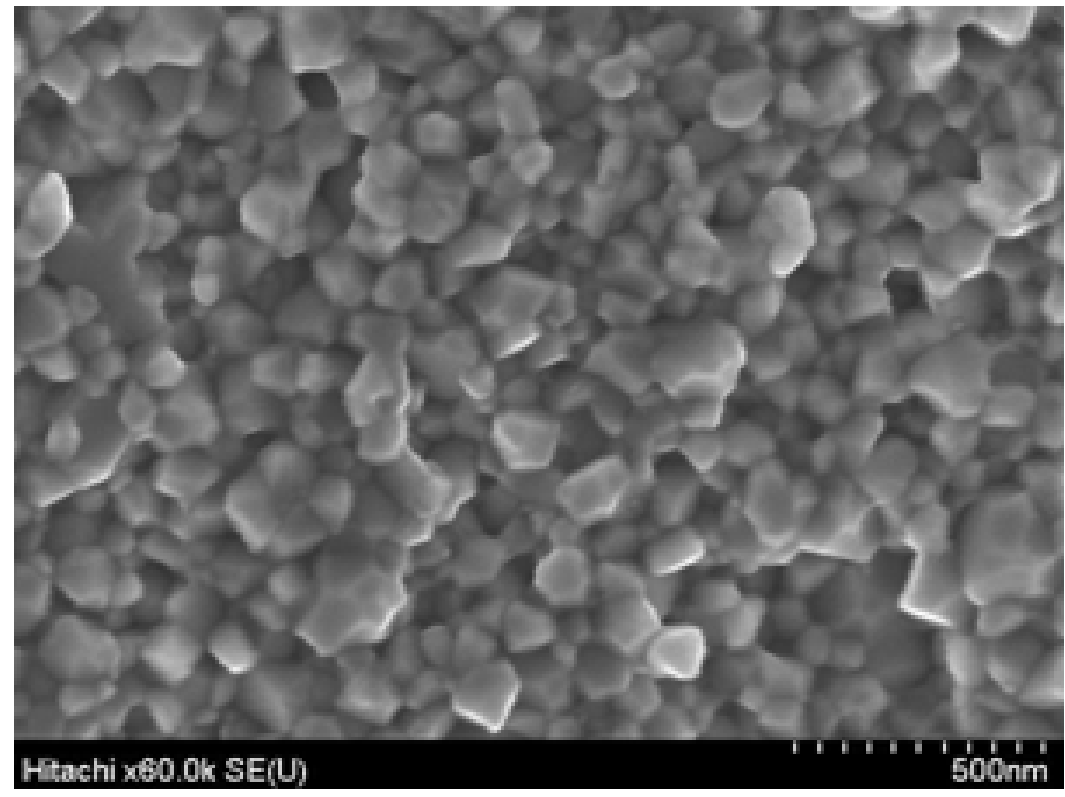

Fig. 6. FESEM micrograph of the as-spun $\mathrm{Nd}_{16} \mathrm{Fe}_{76} \mathrm{~B}_{8} / 30 \%$ wt. $\mathrm{Fe}_{65} \mathrm{Co}_{35}$ sample with speed wheel $v=25 \mathrm{~m} / \mathrm{s}$.

\section{ACKNOWLEDGEMENTS}

The authors gratefully thank the Key Laboratory of Electronic Materials and Devices, VAST, Institute of Materials Science for providing experimental facilities. 


\section{REFERENCES}

[1] R. Coehoorn, D. B. De Mooij, J. P. W. B. Duchateau, and K. H. J. Buchow, J. Phys. (Paris) 49 (1988) C8-669-670.

[2] D. N. Brown, Z. Chen, P. Guschl, P. Campbell, J. Magn. Magn. Mater. 303 (2006) 371 - 374.

[3] I. Ahmad, H. A. Davies, and R. A. Buckley, J. Magn. Magn. Mater. 157/158 (1996) 31 - 32.

[4] Zhongmin Chen, Yong Zhang, George C. Hadjipanayis, Qun Chen, and Baomin Ma, J. Magn. Magn. Mater. 206 (1999) 8 - 16.

[5] G. Mendoza-SuaH rez, J.I. Escalante-GarcmH, J. LoH pez-Cuevas, G. Vargas-GutieHrrez, H. Mancha-Molinar, and J. Mendez-Nonell, J. Magn. Magn. Mater. 206 (1999) 37 - 44.

[6] Choong Jin Yang and Eon Bynng Park, IEEE Trans. Magn. 35 (1999) 3328 - 3330.

[7] Wen-Yong Zhang, Shao-Ying Zhang, A-Ru Yan, Hong-Wei Zhang, and Bao-Gen Shen, J. Magn. Magn. Mater. 225 (2001) 389 - 393.

[8] Akira Arai, Hiroshi Kato, and Koji Akioka, IEEE Trans. Magn. 37 (2001) 2555 - 2557.

[9] Li Shandong, Dai Yaodong, B.X. Gu, Tian Zongjun, and Du Youwei, J. Alloys and Compd. 339 (2002) $202-206$.

[10] M. Daniil, Y. Zhang, H. Okumura, G. C. Hadjipanayis, and D. J. Sellmyer, IEEE Trans. Magn. 38 (2002) 2973 - 2975.

[11] Yang Sena, Song Xiaoping, and Du Youwei, Microelectronic Engineering 66(1) (2003) 121 - 127.

[12] W. Chena, X. Zhao, J. J. Hu, A. J. Li, Y. Tian, G. D. Tang, R. W. Gao, M. G. Zhu, X. M. Li, and W. Li, J. Magn. Magn. Mater. 306 (2006) 51 - 54.

[13] Z. Q. Jin, H. Okumura, Y. Zhang, H. L. Wang, J. S. Munoz, and G. C. Hadjipanayis, J. Magn. Magn. Mater. 248 (2002) 216 - 222.

[14] D. Sultana, M. Marinescu, Y. Zhang, and G. C. Hadjipanayis, Physica B384 (2006) 306 - 309.

[15] A. Melsheimer, M. Seeger, and H. Kronmuller, J. Magn. Magn. Mater. 202 (1999) 458 - 464.

[16] Z.W. Liu and H.A. Davies, J. Magn. Magn. Mater. 313 (2007) 337 - 341.

[17] Yang Bai, Zhang Lei, Shen Baogen, Zhao Tongyun, and Yu Ronghai, J. Rare Earths 31(1) (2013) $49-53$.

[18] X. Y. Zhang, Y. Guan, L. Yang, and J. W. Zhang, Appl. Phys. Lett. 79 (15) (2001) 2426 - 2428.

[19] E. Kneller and R. Hawig, IEEE Trans. Magn. 27 (1991) 3588 - 3600. 